\title{
Air Exposure as a Control Mechanism for the Golden Mussel, Limnoperna fortunei, (Bivalvia: Mytilidae)
}

\author{
G.A. Darrigran \\ División Zoología Invertebrados, Facultad Ciencias Naturales y Museo \\ Paseo del Bosque, 1900 La Plata, Argentina \\ E-mail: invasion@museo.fcnym.unlp.edu.ar \\ M.E. Maroñas \\ Instituto de Limnologia "Dr. Raül A. Ringuelet" \\ Facultad de Ciencias Naturales y Museo - \\ CONICET CC 712 (1900) La Plata, Argentina \\ E-mail: japrea1@infovia.com.ar \\ and \\ D.C. Colautti \\ Facultad de Ciencias Naturales y Museo \\ 122 y 60. (1900) La Plata, Argentina \\ E-mail: dariocolautti@infovia.com.ar
}

\begin{abstract}
We examined the response of the invasive freshwater bivalve Limnoperna fortune $i$ to air exposure under different conditions of relative humidity, at $25.00 \pm 0,4^{\circ} \mathrm{C}$. Survival of $L$. fortunei increased with relative humidity. Specimens exposed to air without humidity control ( 49 to $63 \%$ relative humidity) did not survive more than 120 hours, while those held in an elevated humidity environment survived up to 168 hours. Smaller mussels reached $100 \%$ mortality before larger ones. Consequently, in industrial systems colonized by $L$. fortune $i$, the periodic elimination of water for less than six days will not be an effective control mechanism.
\end{abstract}

\section{INTRODUCTION}

Among the adverse anthropogenic impacts suffered by the Rio de la Plata basin in recent decades has been the introduction of two Asian freshwater bivalve species, Corbicula fluminea (Müller, 1774) or Asiatic clam and Limnoperna fortunei (Dunker, 1857 ) or golden mussel. Of the two species, $L$. fortune $i$ has been the most successful, considering its current dispersion and abundance since the first record of its presence in the Río de la Plata in 1991 (Pastorino et al. 1993, Darrigran and Pastorino 1993, 1995).

Tolerance of aerial exposure and the ability to strongly fix themselves to substrata are characteristics of these mollusks that enable them to exist in tidal systems and to disperse overland between basins (Grifths et al. 1991, Ricciardi et al. 1995, Mansur et al. 1999). Among the problems arising from the presence of $L$. fortunei in South America is the macrofouling which it causes. In Asian countries, the golden mussel is a significant contributor to industrial macrofouling (Morton 1976 and 1996, Ricciardi 1998, Darrigran and Escurra de Drago 2000). Eco-physiologic information about $L$. fortune i is scant. For this reason it has not been possible so far to develop prevention systems or sustainable species management programs. Iwasaki (1997) carried out the first studies about the tolerance of $L$. fortunei to desiccation. Knowledge of the tolerance of this species to different atmospheric conditions can provide important tools to prevent the geographical expansion of the invasion or to control the population densities in affected areas.

We examined, under laboratory conditions, the response of $L$. fortune $i$ to air exposure under conditions of different relative humidity.

\section{MATERIALS AND METHODS}

The mussels were collected in the estuary of the Río de la Plata $\left(34^{\circ} 48^{\circ} \mathrm{S}\right.$, $57^{\circ} 59^{\prime} \mathrm{W}$ ), Argentina. Collection was carried out during low tide, and a spatula was used 
to remove groups of individuals (referred to as "rosettes") that were adhered to the granite rocks. The rosettes were transferred to a container with river water and transported to the laboratory where they were kept in an aerated aquarium with tap water and permanent aeration for at least 48 hours before experimental procedures began. They were fed daily with algae (Scenedesmus spp.) cultivated in the laboratory.

Several evenly sized rosettes were randomly placed in eight $50 \times 30 \mathrm{~cm}$ plastic trays. Experiments were carried out in two stages. In the first stage, two trays were exposed to atmospheric air ( $\mathrm{S} 1$ and $\mathrm{S} 2$ ) and the third lot of rosettes remained as a control $(\mathrm{Cl})$ in tap water with aeration but without food. In the second stage, two trays were exposed to atmospheric air (S3 and S4), and two others were covered with a canvas and humidified to saturation every 24 hours ( $\mathrm{H} 1$ and $\mathrm{H} 2)$. A fifth lot of rosettes was a control (C2) and remained immersed in aerated, phytoplankton-free water. Both experiments were conducted in a closed room without incident sunlight, and the average temperature was $25.0 \pm 0.4^{\circ} \mathrm{C}$. Atmospheric relative humidity ranged between $49 \%$ and $63 \%$, with an average of $55 \% \pm 4.49$.

A rosette was removed daily from each one of the experimental units. The specimens of each rosette were carefully separated by cutting their byssus with a scissors; they were subsequently placed in aerated water. After 18 hours the mussels were observed in order to determine the number of live and dead individuals. Specimens that opened their valves, extended their siphons, or closed their valves when stimulated with a non-piercing object were considered alive. Those that maintained their valves closed or opened but did not react when stimulated were recorded as dead. The percentage of dead specimens was calculated in each sampling and experiment. For each experiment, the percentage of death individuals as a function of time was fitted to the cumulative normal model using the least - squares technique. From this, we calculated the time for $50 \%$ and $100 \%$ specimen mortality. Mortality was also analyzed as a function of size $(<10 ; 10-20$ and $>20 \mathrm{~mm})$ for each experiment.

Valve length (to the nearest $0.1 \mathrm{~mm}$ ) was measured in all specimens. The minimum valve length was $4.02( \pm 0.02 \mathrm{SD}$ ) $\mathrm{mm}$, while the maximum was 29.47 ( $\pm 2.29 \mathrm{SD}$ ) $\mathrm{mm}$. The average number of individuals per rosette was $52( \pm 20 \mathrm{SD})$.

\section{RESULTS AND DISCUSSION}

Specimens belonging to the control groups had $100 \%$ survival throughout the experiments. The time required to effect $50 \%$ mortality of mussels provided with enhanced humidity (covered with canvas) was $104-110 \mathrm{~h}$, whereas the time to $50 \%$ mortality for exposed to atmospheric air mussels was $47-61 \mathrm{~h}$ (Fig. 1).
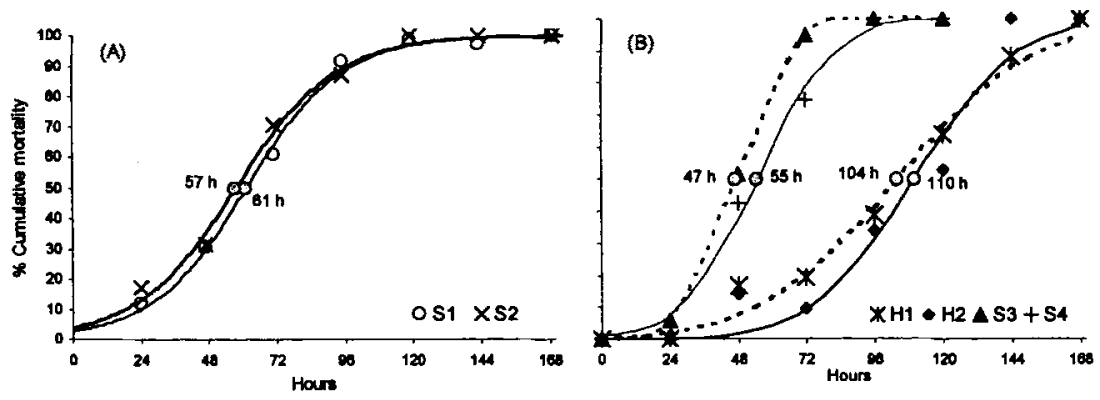

Figure 1. Cumulative percent mortality of $L$. fortunei as a function on exposure time, with adjustments to the cumulative normal model ( $p<0.01$ ) for (A) stage 1 of the experiment and (B) stage 2 . The completely filled circles indicate the time required to reach $50 \%$ mortality. 
Iwasaki (1997) first reported on the ability of $L$. fortunei to survive in the air under laboratory conditions. However, his experimental design did not include control groups so he could not determine if the only cause of mortality was air exposure. In our experiments, the control specimens remained alive until the end of each experiment. Therefore, the results can be attributed to the physiologic stresses of air exposure and reduced humidity.

In the natural environment, these organisms form dense populations that cover hard substrates. According to Iwasaki (1997) this gregarious life mode favors the retention of humidity and attenuates the effects of temperature during air exposure. For these reasons, and considering that one of our aims was to assess the potential use of air exposure as control mechanism, the experiments were carried out using rosettes and not separate individuals as has been done in similar previous experiments with mytilids. (Ricciardi et al. 1995, Iwasaki 1997).

Results obtained when assessing mortality through time for different size categories demonstrate that the youngest components in the populations are less resistant to extended periods of permanent exposure to atmospheric air. This fact allows us to suggest that air exposure, as a control mechanism, is more effective in specimens with valves $10 \mathrm{~mm}$ or less in length.

Mortality as a function of size did not manifest a clearly defined pattern (Table 1); nevertheless, mussels $<10 \mathrm{~mm}$ in length reached a $100 \%$ mortality one day before those $>20 \mathrm{~mm}$ in length. Iwasaki (1997) found that mussels over $20 \mathrm{~mm}$ survived up to 10 days, while our maximum records of survival did not surpass six days. This would be due to the fact that our experiments were conducted in a drier atmosphere (i.e., 49-63\% relative humidity against $\mathbf{7 2 - 8 1} \%$ in Iwasaki's case). These results suggest that survival is linked to humidity. In our second experiments, the periodic increase of humidity up to saturation point increased survival time. This response reflects the adaptive ability of the species to survive in tidal areas where immersion and exposure are part of the daily cycle.

Based on these experiments, we conclude that in industrial facilities densely colonized by $L$. fortunei, the periodic elimination of water for lapses shorter than six days is not sufficient as a control mechanism. To be effective, this method should be accompanied by procedures that reduce environmental relative humidity. In this way it would be possible to generate stress levels capable of producing $100 \%$ mortality in shorter time intervals.

A corollary to these results is the need for implementing sanitary measures for overland transport of elements that have been in contact with aquatic environments invaded by golden mussels. Specimens may survive up to six days in air under environmental conditions similar to those during spring in temperate climates. Therefore, $L$. fortunei could be transported into other environments or basins while attached by the byssus to crafts, nets, fishing equipment, etc. This hypothesis is supported by the dispersion mechanisms of the zebra mussel, Dreissena polymorpha

Table 1 . Time (h) required to reach $100 \%$ mortality in each size category of $L$. fortunei.

\begin{tabular}{lrrrrrrrr}
\hline & \multicolumn{3}{c}{ Replicates exposed to ambient air } & & \multicolumn{2}{c}{ Exposed to saturated humidity } \\
\cline { 2 - 4 } \cline { 8 - 8 } Size category & S1 & S2 & S3 & S4 & & H1 & H2 \\
\hline$<10 \mathrm{~mm}$ & 96 & 96 & 72 & 72 & & 144 & 144 \\
$10-20 \mathrm{~mm}$ & 96 & 96 & 72 & 96 & & 144 & 144 \\
$>20 \mathrm{~mm}$ & 120 & 120 & 96 & 96 & & 168 & 144 \\
\hline
\end{tabular}


(Pallas, 1771), in the northern hemisphere (Nalepa and Schloesser 1993) and it represents an alternative explanation to the wide distribution and rapid upstream dispersion of the golden mussel in South America (Darrigran 2000, Darrigran and Ezcurra de Drago 2000, Darrigran et al. 2000).

\section{ACKNOWLEDGMENTS}

We thank J. Kawatski for constructive remarks and editorial guidance. The present work was partially funded by the Facultad de Ciencias Naturales y Museo (UNLP), the Agencia de Promoción Científica y Tecnológica (PICT 98 N$^{\circ} 01-03453$ IDB 1201/OC-AR); Convenio EBY-FCNyM (UNLP) and Fundación Antorchas (Project 13887-23); PIP Nº 02856.

\section{LITERATURE CITED}

Darrigran, G. 2000 Invasive Freshwater Bivalves of the Neotropical Region. Dreissena 11:7-13.

Darrigran, G. and I Ezcurra de Drago. 2000. Invasion of Limnoperna fortunei (Dunker, 1857) (Bivalvia: Mytilidae) in America. Nautilus 2: 69-74.

Darrigran G. and G. Pastorino. 1993. Bivalvos invasores en el Rio de la Plata, Argentina. Comunicaciones de la Sociedad Malacológica de Uruguay 7: 309-313.

Darrigran G. and G. Pastorino. 1995. The recent introduction of Asiatic bivalve, Limnoperna fortunei (Mytilidae) into South America. Veliger 38: 183-187.

Darrigran G., P. Penchaszadeh, and C. Damborenea. 2000. An invasion tale: Limnoperna fortunei (Dunker, 1857) (Mytilidae) in the Neotropics, pp 219-224 in R. Claudi (ed), Proceeding $10^{\text {th }}$ International Aquatic Nuisance Species and Zebra Mussels Conference. Toronto.

Griffths R.W., D. W. Schloesser, J. H. Leach, and W.P. Kovalak. 1991. Distribution and dispersal of the zebra mussel Dreissena polymorpha in the Great Lakes region. Can. J. Fish. Aquat. Sci. 48:1381-1388.

Iwasaki, K. 1997. Climbing behaviour and tolerance to aerial exposure of freshwater mussel, Limnoperna fortunei. Venus 56 (1): 15-25.

Mansur M, L. Richinitti, and C. Santos. 1999. Limnoperna fortunei (Dunker, 1857) molusco bivalve invasor na Bacia do Guaiba, Rio Grande do Sul, Brasil. Biociências, Porto Alegre 7 (2): 147-149.

Morton, B. 1976. Control of Limnoperna fortunei. Journal of the Institution of Water Engineers and Scientists 30: 147-156.

Morton, B. 1996. The aquatic nuisance species problem: a global perspective and review, pp 1-54 in: Frank D'itri (ed), Zebra mussels and other aquatic nuisance species, Ann Arbor Press.

Nalepa T, and W. Schloesser. 1993. Zebra mussels: biology, impacts, and control. Lewis Publisher, Boca Raton, 508 pp.

Pastorino G., G. Darrigran, S. M. Martín, and, L. Lunaschi. 1993. Limnoperna fortunei (Dunker, 1857) (Mytilidae), nuevo bivalvo invasor en aguas del Río de la Plata. Neotrópica 39: 34.

Ricciardi A. 1998. Global range expansion of the Asian mussel Limnoperna fortunei (Mytilidae): another fouling threat to freshwater systems. Biofouling 13:97-106.

Ricciardi A., R. Serrouya, and F. G. Whoriskey. 1995. Aerial exposure tolerance of zebra and quagga mussels (Bivalvia: Dreissenidae): implications for overland dispersal. Can. J. Fish. Aquat. Sci. 52: 470-477. 